\title{
Distribution, ecology and significance of the genus beeter (merops) in Uzbekistan
}

\author{
Shodieva F.O. ${ }^{\mathrm{a}}$, Kholboev F.R. ${ }^{\text {** }}$ \\ a shodievafo@mail.ru \\ ${ }^{a}$ Researcher. National University of Uzbekistan, Tashkent, Uzbekistan \\ ${ }^{\mathrm{b}}$ Doctor of biological sciences. National University of Uzbekistan, Tashkent, Uzbekistan
}

\begin{abstract}
The study explored the nature of stay, distribution, the number of local territories and the significance of two species (European Bee-eater -Merops apiaster, Blue-cheeked Bee-eater -Merops persicus) of birds of the genus-Merops in Uzbekistan. As a result of the relevant questionnaires, literature materials and our own observations, the significance of the genus Merops in nature and beekeeping farms was determined. In determining their meaning, the main knowledge is removed in the composition of food and trophic behavior of these species. As a result of the data obtained, appropriate recommendations were developed for the protection and snowing of the harmful effects of the genus Merops on beekeeping farms. These recommendations make it possible to prevent illegal catch of bee-eaters, protect them and reduce harmful activity
\end{abstract}

Keywords: repellent, beekeeping, commensalism, lodging, trophic relationship, biocenotic relationship, behavior.

\section{Introduction.}

In recent years, special attention has been paid to the study of the animal world, including the avifauna of urbanized areas. However, in different regions, approaches to studying the distribution, economic value and protection of birds are unique. This situation, especially the underestimation of the value of the species or the lack of information about its conservation status, lead to some acute problems. This applies to the widespread migratory breeding species European Bee-eater -Merops apiaster and Blue-cheeked Bee-eater -Merops persicus from the genus of bee-eater-Merops in Uzbekistan.

According to data, the extermination of these species for the damage they cause in beekeeping farms is widespread not only in Uzbekistan but also in other countries, although M. apiaster is included in the Red Data Books of some states. With the development of beekeeping in the future, the scale of such negative impacts and the problems associated with them may expand.

Based on this, the study of the ecological characteristics of the species of the genus Merops in 
Uzbekistan is relevant in the aspect of determining and assessing their importance in nature and in the economy, as well as preserving their nesting area and number. Identification of adaptive changes in the behavior of populations of these species in local territories makes it possible to develop effective methods of population control.

\section{Materials and methods.}

The material for this work was the results of field studies for the period 2020-2021, conducted in the Tashkent, Bukhara and Samarkand regions of Uzbekistan. The territorial distribution, number and ecological characteristics of the species were studied in natural landscapes, nesting colonies, beekeeping farms and agrocenoses. Counting of birds was carried out at the corresponding stationary sites and routes. For the quantitative registration of birds, the route method and the method of point counts were used [3,5].

\section{Results and its discussion.}

The beginning and end of spring and autumn migrations of these species in different years ranges from 15 to 20 days. The earliest spring migration of M. apiaster in Uzbekistan was recorded on April 15, and autumn migration on September 6. In the south of the republic, they will be delayed until October 15. Accordingly, M. persicus on April 10, October 29 [4,6].

According to our observations in 2021, in the Tashkent region, the first individuals of M. apiaster were recorded on April 22. In 2020, in the Bukhara region, the first specimen of M. persicus was recorded on April 7, and in 2021 on April 16. During the autumn migration period 2014-2020. the last individuals of this species in this region were registered on October 9-26. In recent years, an increase in the residence time of species of the genus Merops has been observed in Uzbekistan, and this is due to global warming. This is evidenced by the expansion of their nesting areas in the northern direction [1].

According to the literature data, the abundance of M. apiaster in the south of the country is greater than that of M. persicus [6]. In our studies, these data were not confirmed. And so, although during migration both these species are found unevenly in the republic, after migration M. apiaster occupies the northeastern mountainous and foothill areas, and M. persicus the plain areas located in the southern and western parts of the republic. In addition, M. apiaster is found on the coasts of large rivers, in spite of where they were not found. In transitional ecosystems, these species form mixed nesting colonies. After migration, the redistribution of these species, as well as their migration after the reproductive cycle, is closely related to trophic and topical conditions.

The reproductive cycle of these species proceeds mainly in natural landscapes, but some pairs of $\mathrm{M}$. persicus nest in even rural settlements. After the reproductive cycle (at the beginning of august), both species leave their nesting site, since during this period natural landscapes, especially those in arid regions, sharply reduce the species diversity and the number of insects, which are the main food object. And also, the number of both species increases sharply due to the emerged chicks. During this period, associated with climatic 
conditions in natural ecosystems, numerous insects disappear and such an ecosystem cannot satisfy the food needs of birds.

In this regard, these species are redistributed (pumped out) in agrocenoses and beekeeping farms, where many insects and bees are still preserved, especially they are concentrated in large quantities in beekeeping farms. Thus, in Uzbekistan, depending on the change in the trophic relations of these species, the habitat, the number, and the associated practical value also change (table). This is evidenced by their trophic behavior and food spectra. It is during this period (august, september) that these species are harmful to beekeeping.

According to the results of accounting in different biocenoses, the number of M. apiaster per 10 hectares of the area ranges from 0,4-7,6 pieces, respectively, M. persicus 0,07-6,3.

Table 1. Average abundance of M. apiaster and M. persicus in different biocenoses of Uzbekistan (2020-2021)

\begin{tabular}{|c|c|c|c|c|c|c|c|c|}
\hline \multirow[t]{2}{*}{ Biocenoses } & \multicolumn{7}{|c|}{$\begin{array}{l}\text { Months, average number of birds (individuals per } 10 \text { ha. } \\
\text { area) }\end{array}$} & \multirow{2}{*}{$\begin{array}{l}\text { Average } \\
\text { annual } \\
\text { number }\end{array}$} \\
\hline & IV & $\mathrm{V}$ & VI & VII & VIII & IX & $X$ & \\
\hline \multicolumn{9}{|c|}{ Merops apiaster } \\
\hline Natural landscapes & 0,02 & 0,4 & 1,6 & 0,7 & 0,3 & 0,1 & - & 0,4 \\
\hline Agrocenoses & 0,2 & 2,1 & 2,4 & 3,8 & 5,5 & 7,6 & 1,9 & 3,3 \\
\hline Rural settlements & 0,05 & 2,6 & 3,8 & 5,5 & 5,9 & 6,6 & 1,5 & 3,7 \\
\hline Beekeeping & 0,06 & 3,4 & 5,3 & 8,7 & 19,0 & 14,3 & 2,9 & 7,6 \\
\hline \multicolumn{9}{|c|}{ Merops persicus } \\
\hline Natural landscapes & - & 0,02 & 0,3 & 0,1 & 0,07 & 0,03 & - & $\mathbf{0 , 0 7}$ \\
\hline Agrocenoses & 0,01 & 0,9 & 1,1 & 2,3 & 3,8 & 4,1 & 0,02 & 1,7 \\
\hline Rural settlements & - & 0,4 & 0,8 & 1,3 & 2,3 & 3,0 & 0,03 & 1,1 \\
\hline Beekeeping & - & 1,2 & 1,7 & 8,9 & 14,4 & 17,1 & 1,4 & 6,3 \\
\hline
\end{tabular}

There are no materials in the literature on the values of the genus Merops in the natural conditions of

Uzbekistan. According to our observations, both species of the genus Merops are of great importance in nature and in human economic activity. Especially, in biocenoses, the arid zone of Uzbekistan, where many factors (deficiency of nesting place and food resources, severe climatic conditions, etc.) are at a critical level, the relationship of organisms becomes more complicated, and the role of each species increases.

Commensalism is one of the important biocenotic relationships of bee-eaters in the biocenosis. One form of lodging commensalism is observed in old nests of bee-eaters. Many species of Arthropoda and Chordata (Phrynocephalus interscapularis, Trapelus sanguinolentus, Cyrtopodion russowi, Coliber karelini, Eryx miliaris) were found in such nests. These and other species in such nests are reliably protected from predators and from unfavorable climatic conditions [2,8]. When studying the nesting colony of M. persicus located in the Kyzyl Kum desert, it was found that the old nests of this species are used for nesting by Rollers - Coracias garrulus, Acridotheres tristis, Passer indicus and field Passer montanus sparrows. This kind of relationship like lodging is important in biodiversity conservation.

Freelogging is another form of commensalism characteristic of the nesting life of bee-eaters. When examining in the lower part of the inlets, inlets and nesting chambers of bee-eaters, food waste and pellets are found. These objects are food resources for the ant, which feeds on this food waste. This relationship ensures 
the formation and stability of the food chain in the biocenosis.

The trophic relationship of bee-eaters in the biocenosis is very diverse and complex. Bee-eaters, when chasing, ambushing and other behaviors while hunting insects and bees, demonstrate behavior characteristic of predatory animals. It should be noted that bees also respond to the sounds of a bee-eater and exhibit behavior typical of prey. In turn, the bee-eater also becomes the stings of some species (Vulpes vulpes, Canis aureus, Falco naumanni, Circus aeruginosus, Varanus griseus, Coluber karelini and Coluber ravergieri). Which are hunted by adults, chicks and bee-eater eggs near nesting colonies and in bee-eater nests. In 2020, in one of the nesting colony located in an old quarry in the Bukhara region, in a burrow of a green bee-eater M. persicus, a gray monitor lizard, Varanus griseus, was found swallowing an adult specimen of a green bee-eater. Not far from this colony, a fox burrow, Vulpes vulpes, was found, near which M. Persicus feathers and other food waste were found. When examining the nests in the holes of some holes, traces of the claws of predatory animals were found and these data indicate that this species is a food item for some animals.

As a result, bee-eater predation is involved in the regulation of the number of insects, causing some damage to the beekeeping economy, and the carnivorous animal is involved in the regulation of the number of bee-eaters. As a result, this type of relationship ensures the integrity of the food chain and its stability. Thus, M. persicus and M. apiaster, as environment-forming species, actively participate in biotic relations and are important in maintaining the stability of ecosystems.

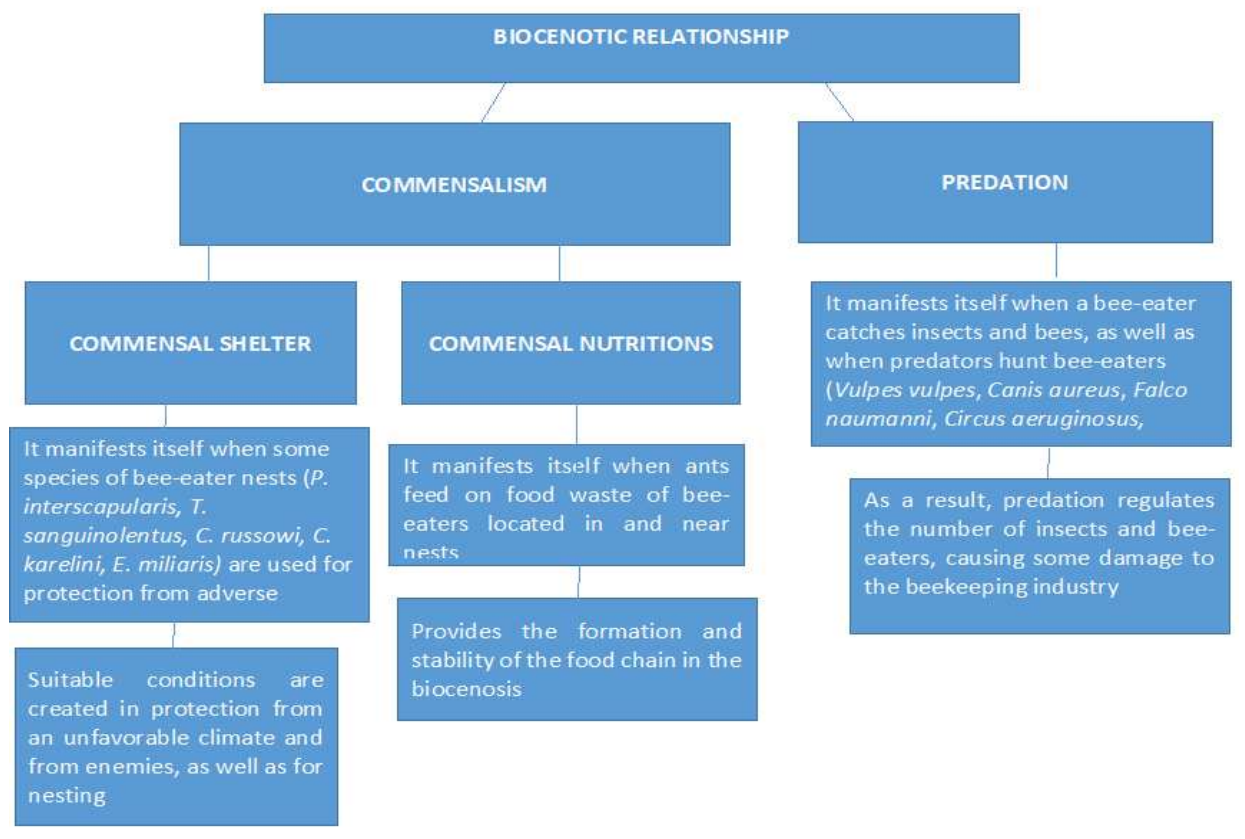

Fig. 1. Participation of the genus Merops in biocenotic relationships

It should be said that in many countries, including Uzbekistan, M. persicus and M. apiaster is 
considered the main pest of beekeeping farms and therefore they are scared away or destroyed using different methods (shooting, catching with nets, destroying nests). Sometimes various optical and acoustic devices are used to scare away. According to our observations and survey results, only in Bukhara region for 2016-2018. approximately more than 10 thousand individuals of $\mathrm{M}$. persicus were shot, and this is more than any other species of animals that were shot illegally during this period [9]. Although, M. apiaster is included in the Red Data Books of the Vladimir region of Russia, the Republic of Tatarstan, the Republic of Belarus and others.

Such an attitude towards the species of the genus Merops and a one-sided assessment of their importance require further development of appropriate measures to control their behavior and protect these species from illegal destruction.

It should be noted that when studying and assessing the significance of the genus-Merops, one should take into account the factors regulating their distribution and behavior. Analyzing the preliminary data, we can say that the species of the genus Merops in Uzbekistan have double meanings: in the reproductive cycle, destroying harmful insects, they bring great benefits to agriculture, after the reproductive cycle, destroying bees will create some problems.

\section{Recommendation.}

The following recommendations have been developed for the management of the behavior of $\mathrm{M}$. apiaster and M. persicus in beekeeping farms and their protection in the conditions of Uzbekistan:

- within a radius of $3 \mathrm{~km}$. beekeeping enterprises to prevent (reclamation of quarries, ravines, closed openings of nests) the formation of a nest colony;

- $\quad$ to protect bees from M. persicus in lowland areas, take measures to move hives in mountainous and foothill zones, taking into account the reproductive cycle, seasonal variability of trophic and topical relationships of birds;

- introduction of scientifically grounded and effective use of bioacoustic repellents in order to prevent the accumulation of bee-eaters in beekeeping farms and the study of advanced international experience in this area;

- $\quad$ strictly limit shooting and other methods of destruction of bee-eaters and evaluate such actions as poaching.

\section{Conclusions}

M. apiaster and M. persicus in beekeeping M. apiaster and M. persicus are widespread migratorybreeding species for Uzbekistan. As a habitat, M. apiaster usually prefers mountainous and foothill territories, M. persicus prefers the flat zone of the republic. The distribution, number and significance of these species in different regions of Uzbekistan is variable and this is overestimated from the topical and trophic relations, as well as from the reproductive cycle. The uneven distribution of these species is explained by the specificity of the qualitative and quantitative characteristics of the climate, relief and ecological conditions of the habitat for 
each ecosystem. Improvement and use of the developed recommendations in practice can limit illegal hunting of these species and reduce their damage in beekeeping.

\section{References}

1. Vinogradov A.A., Zinoviev A.V. The first known case of nesting of the golden bee-eater (Merops apiaster L.) in the Tver region // Vestnik TVGU. Series "Biology and Ecology". -№2, 2014- C.38-47].

2. Malovichko L.V., Konstantinov V.M. Comparative bird ecology: ecological and morphological adaptations. Stavropol-Moscow: SSU Publishing House, 2000 .- 288 p.

3. Morozov NS Methodology and methods of accounting in studies of the structure of bird communities: some critical considerations // Successes of modern biology. - M.: Nauka, 1992 .-- T. 112, no. 1. - S. 139 - 153.

4. Birds of Central Asia. Volume 1. - Almaty, 2007 .-S. 506-516.

5. Ravkin E.S., Chelintsev N.G. Methodical recommendations for integrated route accounting of birds // M .: Publishing house. VNII Nature. 1990. -33 p.

6. Sagitov A.K. Family Shchurkovye - Meropidae. Birds of Uzbekistan. Volume 2. Tashkent: Fan, 1990. - S. 270-278.

7. Sema A.M., Shimov S.V. Regulation of the placement of corvids with bioacoustic repellents in Kazakhstan // Mat. 1 meeting on ecology, biocenotic and economic significance of corvids. - Moscow, 1984. - S. 194-196.

8. Casas-Crivlle A., Valera F. The European bee-eater (Merops apiaster) as an ecosystem engineer in arid enviornments. Journal of Arid Enviornments. - 60 (2): 2005. -R. 227 238.

9. Kholboev F.R., Shodieva F.O, Mirkhonova Z.P. Hunting animals of the Bukhara region and issues of their rational use. International Journal of Research Publications (IJRP.ORG), 2021,-Vol. 69, Iss. 1. ISSN: 2708-3578, pp. 556-564 